\title{
Ocorrência da Sigatoka Negra em Bananeira Causada por Mycosphaerella fijiensis no Estado de Mato Grosso
}

\author{
Napoleão S. de Souza \& Emir Feguri \\ Empresa Mato-grossense de Pesquisa, Assistência e Extensão Rural S/A, Rua do Pintado, S/No - Bairro Ponte Nova, \\ CEP 78115-100, Várzea Grande, MT, e-mail: napo.souza@bol.com.br
}

(Aceito para publicação em 06/01/2004)

Autor para correspondência: Napoleão Silvino de Souza

\begin{abstract}
Occurrence of Black Sigatoka caused by Mycosphaerella fijiensis in banana in the State of Mato Grosso, Brazil

The banana (Musa spp.) culture in the Southwest region of Mato Grosso, Brazil, has been affected by a disease whose symptoms begin as small brownish-red lesions in the lower face of the leaf. As the disease progresses, the lesions lengthen into grooves, which eventually become eliptical dark spots with green

halos associated with Mycosphaerella fijiensis (anamorfa Paracercospora fijiensis). The initial diagnosis, based on the simptoms, was confirmed in the laboratory using an optical microscope where fungal structures associated with diseased leaves were detected. The samples analyzed were first collected in the district of Cáceres and later from 18 others municipalities in the State of Mato Grosso.
\end{abstract}

Mato Grosso é um dos principais produtores de banana (Musa spp.) no Brasil e sua produção é utilizada para o consumo "in natura" e para comercialização em outros estados. Porém, com a ocorrência da Sigatoka negra, em 1999, em Cáceres, MT, ocorreram proibições de comercialização das bananas das áreas infestadas para as demais regiões consideradas livres da doença. Atualmente, o patógeno encontra-se disseminado em mais 18 municípios (Figura 1A). O Estado obteve do Ministério da Agricultura Pecuária e Abastecimento - MAPA, o reconhecimento de dois locais de produção livre de Sigatoka negra do Brasil, a Gleba Macife, em Ribeirão Cascalheira, e Vale do Iriri, em Guarantã do Norte. Sendo os únicos locais autorizados a comercializar a produção de banana no país (Figura 1A). Os sintomas iniciam com pequenas lesões de coloração marromavermelhadas na face inferior da folha, que se alongam em estrias e se estendem em manchas maiores, tornando-se, posteriormente, elípticas com coloração escura e halo verde, em grande número, ao longo da nervura principal. Na detecção da doença, realizaramse estudos morfológicos em folhas de bananeira, cv. Maçã, com sintomas da Sigatoka negra, coletada em Cáceres-MT. No exame das estruturas do agente etiológico utilizaram-se raspagens feitas com estilete sob lupa, fita durex, bem como cortes histológicos feitos a mão livre. Utilizou-se como corante, o lactofenol de Amann, mais azul de algodão. Os cortes das folhas foram colocados em Becker de $50 \mathrm{ml}$ com lactofenol e submetidos a fervura por $3 \mathrm{~min}$. Em seguida, os pedaços de folhas foram colocados em lâminas com uma gota de azul de algodão mais lactofenol e posteriormente foi feita observação ao microscópio óptico para visualização dos conidióforos emergindo dos estômatos, na face abaxial das folhas. $\mathrm{O}$ exame do material infetado revelou que o fungo presente nas lesões corresponde a Paracercospora fijiensis (Morelet) Deighton, forma anamórfica de Mycosphaerella fijiensis (Morelet), que causa a doença
Sigatoka negra em folha de bananeira (Wardlaw, C. W. Banana diseases including plantains and abaca. 1972). O fungo apresentou duas características morfológicas marcantes (Figura 1B): no estádio assexual ocorrem conidióforos isolados ou em pequenos grupos (dois a oito), e existe uma cicatriz na base do conídio (hilo basal) coincidindo com a diagnose descrita na literatura para M. fijiensis. Os conídios são do tipo obclavulado a cilíndrico que se mostraram eretos ou ligeiramente curvos e multisseptados (Figura 1B). Os conidióforos apresentaram-se septados emergindo a partir de estômatos na face inferior da folha (Figura 1C).

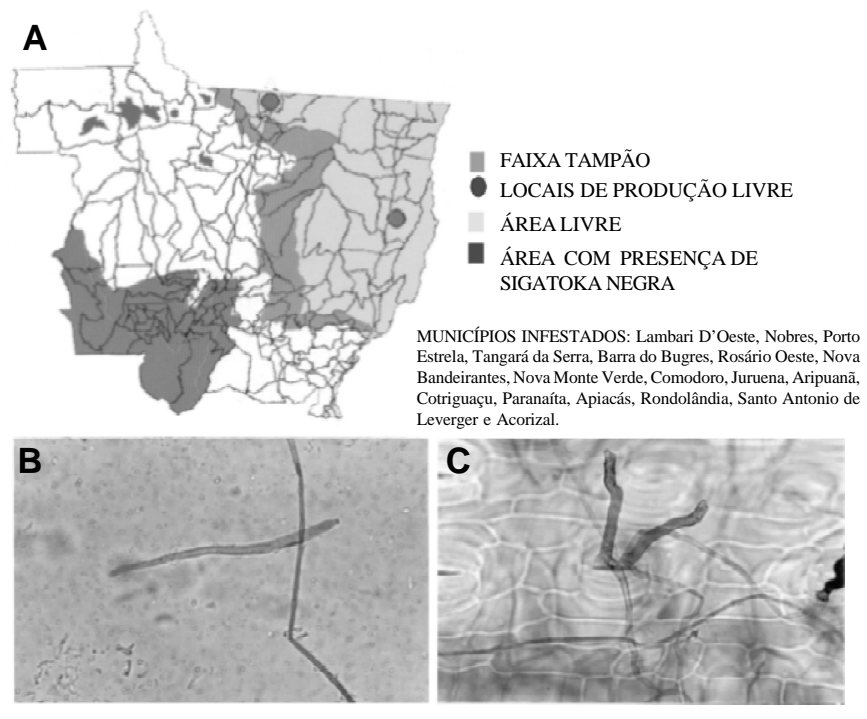

FIG. 1 - A- Municípios do Estado de Mato Grosso, com área afetada, área livre e locais de produção livre de banana (Musa spp.) (Fonte: INDEA-MT); B - conídio de Paracercospora fijiensis; C conidióforos de P. fijiensis emergindo de um estômato. 